From the Department of Veterinary Virology and Immunology and Department of Veterinary Pathology, Royal Veterinary and Agricultural University, Copenhagen, Denmark and Danish Fur Breeders Association, Glostrup, Denmark.

\title{
Treatment of Neonatally Aleutian Disease Virus (ADV) Infected Mink Kits with Gammaglobulin Containing Antibodies to ADV Reduces the Death Rate of Mink Kits
}

\author{
By Bent Aasted, Søren Alexandersen and Mogens Hansen
}

\begin{abstract}
Aasted, B., S. Alexandersen and M. Hansen: Treatment of neonatally Aleutian disease virus (ADV) infected mink kits with gammaglobulin containing antibodies to ADV reduces the death rate of mink kits. Acta vet. scand. 1988, 29, 323-330. Aleutian disease virus (ADV) can cause pneumonitis in newborn kits up to 3 weeks old. In many cases the pneumonitis is fatal, but can be reduced by treatment with antibodies to ADV. The present report describes antibody therapy in both experimentally infected mink kits and in mink kits from a farm, where an ADV epidemic developed during the whelping period in the spring of 1987. In both cases the antibody treatment was found to have a beneficial effect on the survival rate of the mink kits. One hundred percent survival rate was found for the experimentally infected mink kits. The most pronounced effect for the naturally infected mink was found in the wildtype mink kits, where the death rate was $9.6 \%$ for the antibody treated group versus $16.9 \%$ for the untreated group $(p<0.001)$. In general the success rate of the gammaglobulin treatment seemed to correlate with the ADV-infection level in the mink sheds. The highest success rate was found in the sheds with the highest ADV-infection level (the standard and wildtype mink), while no effect whatsoever was found for the pearl mink, which were placed in a shed with a low ADV-infection level.
\end{abstract}

parvovirus; pneumonitis; ADV prevention; mortality.

\section{Introduction}

Aleutian disease (ADV), a non-defective parvovirus (Bloom et al. 1980), causes two kinds of infection. In adult mink the disease is characterized by plasmacytosis, hypergammaglobulinemia and immune complex mediated glomerulonephritis and arteritis (for reviews see Porter et al. 1980, Lodmell \& Portis 1981, Aasted 1985). In newborn kits up to 3 weeks of age ADV can cause pneumonitis (Larsen et al. 1984, Alexandersen 1986). In many cases the pneumonitis is fatal, while surviving kits develop the classical (adult) form of plasmacytosis.

All vaccination efforts to prevent $A D$ have failed. Mink vaccinated with formaldehyde inactivated virus-containing material did not demonstrate increased resistance to infection, when later challenged with virulent virus (Karstad et al. 1967). Porter et al. (1972) reported that vaccination even increased the severity of the disease. Passive administration of antibody to virus at the peak of virus replication was shown to pro- 
duce necrotizing acute lesions, followed by mononuclear cell infiltrates (Porter et al. 1972). These results can best be explained by the observation of Porter \& Larsen (1967) that virus cannot be neutralized by antibodies, but exist as infective immune complexes. Vaccination or passive antibody therapy has therefore no effect on the classical AD.

Experiments by Alexandersen (1986) showed that experimental induction of the interstitial pneumonitis in newborn mink kits was only possible in kits from dams free of $\mathrm{AD}$, whereas kits from ADV-antibody positive dams did not develop lung changes, but only classical AD. This indicated that immunity could prevent lung infections. Vaccination studies or studies with passive antibody therapy in connection with ADV-infection in newborn mink kits should therefore be performed.

The present report describes antibody therapy in both experimentally ADV-infected mink kits and in mink kits from a farm where an ADV-epidemic developed during the whelping season in the spring of 1987 . In both cases the gammaglobulin treatment was found to have a beneficial effect on the survival rate of the mink kits.

\section{Materials and methods \\ Mink}

All dams with their mink kits used in this study were housed in separate cages and fed a standard mink diet.

For the experimental infection 44 mink kits born of 9 standard mink dams were infected within $72 \mathrm{~h}$ after birth. The pregnant mink were obtained from an AD-negative farm and found to be free of ADV-antibodies before experimentation as judged by line immunoelectrophoresis (see later). The mink kits were inoculated intraperitoneally with
$0.1 \mathrm{ml}$ of a 1:100 dilution of an ADV preparation ( $\mathrm{K}$ isolate, see later).

Altogether 5103 mink kits of 3 different types (standard, pearl, wildtype) were used for the farm investigation. The standard and wildtype mink were placed in 3 different sheds, while the pearl mink were placed in a fourth. The mink from this farm used to be AD-negative as judged by counter current immunoelectrophoresis (CCIE), but in February 1987 AD-positive mink were found. Although action was taken to eradicate infected mink, the farmer was not able to eliminate all positive reactants at the time of breeding. This resulted in a high percentage of barren females and development of pneumonitis among the kits.

Approximately half of the mink kits were treated with gammaglobulin (i. m.). In order to save as many mink kits as possible we decided only to treat mink kits born after May 1st. The treatment was performed on May 18th. All mink born before May 1st served as controls. By doing so we realized that we introduced a bias in the experiment, but observations from previous years on similar outbreaks indicated that the death rate of mink kits seemed to remain fairly constant throughout the breeding period. We had therefore no reservations in treating the youngest kits and leaving the oldest as controls. However, we left 517 wildtype mink kits untreated irrespective of whether they were born before or after May 1st. They were placed in the same shed as the pearl mink. The mortality recording was done on July 15 for all mink.

\section{$A D V$-isolates}

The $\mathrm{K}$ isolate of $\mathrm{ADV}$ was isolated from the first episode of pneumonitis in Denmark in 1982 (Bøtner \& Jørgensen 1983, Jørgensen \& Bøtner 1983, Larsen et al. 1984, Alexandersen 1986). Lungs from dead kits were 
collected and a partly purified ADV-preparation was prepared by tissue homogenization, Freon extraction and ultracentrifugation according to Cho \& Ingram (1974). The virus preparation had a virus concentration comparable to the one used for CCIE.

With regard to the natural outbreak of ADV on the mink farm described in this study, no attempts were made to purify the virus. Danish ADV-isolates are, however, reported to be highly virulent (Aasted 1985).

\section{Gammaglobulin preparation}

Blood was collected from a large number of ADV-infected mink and the serum pool isolated. Ammonium sulphate was added to a concentration of $25 \%(w / v)$. After $3 \mathrm{~h}$ incubation with constant stirring at room temperature the mixture was centrifuged at $3000 \mathrm{~g}$ for $30 \mathrm{~min}$. at room temperature. The supernatant was discarded and the pellet was washed once with $0.75 \mathrm{~mol} / \mathrm{l}$ ammonium sulphate. The pellet was dissolved in PBS and this solution was ultracentrifuged twice at $125000 \mathrm{~g}$ for $2 \mathrm{~h}$. The supernatant was adjusted to a protein concentration of $22 \mathrm{mg}$ per $\mathrm{ml}$ and checked for bacterial contamination on blood agar plates. No bacterial colonies were isolated. $1 \mathrm{ml}$ of the preparation was injected into each of 3 standard indicator mink. The mink were tested monthly for presence of antibodies to ADV and found to be negative throughout a half year test period. We therefore concluded that the preparation was essentially free of ADV.

Counter current line absorption immunoelectrophoresis (CCLAIE)

The counter current line absorption immunoelectrophoresis (in short: line immunoelectrophoresis) was used to detect antibodies to ADV as well as ADV antigen. The technique has previously been described (Aasted et al. 1986).
Lungs from 10 dead mink kits collected from the ADV infected mink farm on the day of gammaglobulin treatment were homogenized in saline and analyzed for presence of free ADV antigen by the CCLAIEtechnique. ADV (or ADV-related antigens) was found in lungs of 8 out of the $10 \mathrm{mink}$ kits.

\section{Statistical analysis}

Chi-square analyses were performed.

\section{Results}

Gammaglobulin treatment of experimetally infected newborn mink kits

Forty-four mink kits from 9 ADV-negative dams were infected neonatally with ADV strain $\mathrm{K}$. The kits from 3 dams received 0.1

Table 1. Mortality of gammaglobulin treated and untreated, neonatally ADV-infected mink kits ${ }^{\mathrm{a}}$.

\begin{tabular}{lcc}
\hline Group ${ }^{\text {b) }}$ & No. of kits borm & No. death \\
\hline Group 0 & 5 & 0 \\
Group 0 & 3 & 0 \\
Group 0 & 3 & 0 \\
Group 5 & 5 & 0 \\
Group 5 & 7 & 0 \\
Group 10 & 3 & 0 \\
Group 10 & 8 & 0 \\
Control & 8 & $8^{\mathrm{c})}$ \\
Control & 2 & $2^{\mathrm{c}}$ \\
\hline
\end{tabular}

a) All mink kits received 1 ul partially purified ADV preparation on 100 ul saline (i. p.).

b) The gammaglobulin treated mink kits (groups 0,5 , and 10 ) were treated day 0 (simultaneously with ADV injection) day 5, and day 10 after ADV injection. The gammaglobulin injections (i. m.) were followed up by injections on day 3 and on day 5 (after first gammaglobulin injection). The control mink kits received no gammaglobulin treatment.

c) 4 mink kits died on day 17 after ADV injection, 2 on day 19,1 on day 20 and 2 mink kits on day 22 . 
ml gammaglobulin i. m. immediately after the virus inoculation (given ip.) followed by further injections of gammaglobulin on day 3 and day 5 (see Table 1). Twelve mink kits from 2 dams received the first gammaglobulin treatment 5 days after virus inoculation. Eleven mink kits from 2 dams received the first gammaglobulin 10 days after virus inoculation. Finally 10 mink kits from 2 dams did not receive gammaglobulin treatment at all and served as controls. The results are presented in Table 1. None of the mink kits treated with gammaglobulin died of pneumonitis, whereas 9 of the 10 mink kits, which did not receive gammaglobulin treatment, died of the disease. The single surviving mink kit died 1 month after virus inoculation from unknown causes. The results show that there is a $100 \%$ survival rate of the mink kits treated with gammaglobulin, while 9 out of the 10 non-treated mink kits died of pneumonia. All the surviving mink kits became positive for antibody to ADV; an indication that the mink were infected with virus.

\section{Treatment of naturally ADV-infected} newborn mink kits with gammaglobulin The results from the experimentally infected mink kits strongly indicated the need for a follow-up study on a mink farm with newly diagnosed ADV-infection. In 1987 there was only 1 mink farm in Denmark, where the ADV infection was reported in time for experimental gammaglobulin treatment. Two other mink farms had ADV-outbreaks during the breeding period, but the pneumonitis was diagnosed too late. The mink farm was originally AD-negative, but in February positive mink were found. These were pelted, but at breeding time new AD-positive animals were found. The farmer was thus forced to breed ADV-infected animals. Three different types of mink (standard, pearl, and wildtype) were bred. The highest infection rate was noted in the standard and wildtype

Table 2. Mortality of gammaglobulin treated and untreated, naturally ADV-infected mink kits ${ }^{a}$.

\begin{tabular}{lcrrr}
\hline & & \multicolumn{3}{c}{ Number of kits } \\
\cline { 3 - 5 } Minktype & $\begin{array}{c}\text { gammaglob. } \\
\text { treatment }\end{array}$ & $\begin{array}{c}\text { on } \\
\text { May 18 }\end{array}$ & \multicolumn{1}{c}{ on } & July 15 \\
\hline Standard & & 1146 & 964 & $182(15.9)^{\mathrm{c})}$ \\
Standard & + & 1098 & 887 & $211(19.2)^{\mathrm{c})}$ \\
Pearl & + & 541 & 489 & $52(9.6)^{\mathrm{d})}$ \\
Pearl & - & 895 & 824 & $71(7.9)^{\mathrm{d})}$ \\
Wildtype & + & 1115 & 1008 & $\left.107(9.6)^{\mathrm{e}}\right)$ \\
Wildtype & - & 308 & 256 & $52(16.9)^{\mathrm{e})}$ \\
\hline All & + & 2802 & 2461 & $341(12.2)^{\mathrm{f}}$ \\
All & - & 2301 & 1967 & $334(14.4)^{\mathrm{f}}$ \\
\hline
\end{tabular}

a) Some treated mink kits were born up to 18 days before treatment.

b) Only one gammaglobulin injection was given $(0.1 \mathrm{ml} \mathrm{i.} \mathrm{m}$.)

c) Significantly different $(p=0.038)$.

d) Not significantly different $(\mathrm{p}=0.271)$.

e) Significantly different $(\mathrm{p}<0.001)$.

f) Significantly different $(p=0.014)$. 
mink. A rather high rate of barren females was also observed. Altogether $13.6 \%$ of the standard mink, $10.0 \%$ of the pearl mink, and $21.3 \%$ of the wildtype mink failed to produce offspring. This is in agreement with the study of Alexandersen (1986), where it was shown that mink infected during pregnancy loose their foetuses.

Altogether 5103 mink kits were used for experimentation. Approximately half of them (all mink kits born after May 1st) were treated with gammaglobulin. The mortality of the gammaglobulin treated (and nontreated) naturally ADV-infected mink kits is shown in Table 2.

The gammaglobulin treatment only reduced the death rate significally in the standard and wildtype mink kits, while it had no significant effect in the pearl mink kits.

Five hundred and seventeen wildtype mink kits were left untreated to obtain the basal death rates for mink kits born before and after May 1st. The death rates of the untreated wildtype mink kits showed that $4.0 \%$ of the mink kits born before May 1st died, while $8.1 \%$ of the mink kits born after May 1st died, indicating that the ADV infection level increased with time during the whelping period.

\section{Discussion}

Treatment with gammaglobulin of both experimentally and naturally ADV-infected newborn mink kits decreased the overall death rate. While the studies from the experimentally infected mink kits showed a 100 per cent survival rate after gammaglobulin treatment, on the average $12.2 \%$ of the treated mink kits from a farm with a newly diagnosed ADV-infection, died of pneumonitis. If left untreated, $14.5 \%$ of the mink kits died of pneumonitis.

The success rate of the gammaglobulin seemed to correlate with the ADV-infection level (as judged by the mortality rate) in the shed. The highest success rate was found in the sheds with the highest ADV-infection level (the standard and wildtype mink), while no effect whatsoever was found for the pearl mink, which were in a shed with a low ADV-infection level (Table 2).

The gammaglobulin treatment of the naturally ADV-infected mink kits seems relatively ineffective when compared to the $100 \%$ survival rate in the experimentally infected mink. There are several reasons for this poor but still positive effect of gammaglobulin treatment.

One hundred per cent survival rate of ADV exposed mink kits cannot be expected. Some of the mink kits were born 18 days before gammaglobulin treatment. Among the experimentally infected non-gammaglobulin treated mink kits 4 kits died on day 17 after infection, 2 on day 19,1 on day 20 and 2 kits on day 22 (see the Table 1 legend). Therefore it is to be expected that if some of the mink kits were infected within a day or two of birth they could already be moribund on day 18 after birth; the day of gammaglobulin treatment on the farm. Some of the mink kits have simply been too severely damaged by the infection to survive even after receiving gammaglobulin.

The mortality rate of the untreated wildtype mink kits showed that the ADV-infection level increased with time in the whelping period. Only $4.0 \%$ of the untreated mink kits born before May 1 st died, while $8.1 \%$ of the mink kits born after May 1st died. In other words, if the mink kits born after May 1st had not been treated with gammaglobulin, 2 $\times 14.5 \%$, i.e. $29 \%$ of them might have been expected to die, if the infection level in standard and pearl mink showed a corresponding increase in magnitude on the farm during the whelping time. Seen in relation to this percentage, the $12.2 \%$ death rate found 
in the gammaglobulin treated mink kits seems a reasonably good result.

The fact that the ADV infection level increased with time in the whelping period also explains why the lowest mortality rate and lowest success rate of the gammaglobulin treatment was found in the pearl mink. The results from Table 2 clearly shows, that pearl mink do give birth earlier than standard- and wildtype mink. Most pearl mink kits were born before May 1 and those born after were mainly born in the early part of May. It is clearly in this group of mink where the lowest success rate of the gammaglobulin treatment would be expected. The results presented in Table 2 verify this. The treatment did not have any effect in the pearl mink kits.

The opposite situation is observed in the wildtype mink kits. These kits were clearly the latest born kits (most of them were born between May 8-18). A large part was therefore newborn at the time of gammaglobulin treatment. It is in this group of mink kits that the highest success rate of the gammaglobulin would be expected as also the results from Table 2 show.

Another explanation for the $12.2 \%$ death rate of the naturally infected mink kits was that only one gammaglobulin treatment was given. The experimentally infected, gammaglobulin treated mink kits received 3 injections of gammaglobulin, the follow-up injections being given on days 3 and 5 after the first injection. From a practical point of view it is not convenient to give more than 1 injection of gammaglobulin and therefore the mink kits on the farm did not receive the same concentration of passive antibody to $\mathrm{ADV}$ as the experimentally infected mink kits.

Due to the overall positive effect of the gammagiobulin treatment, follow-up studies must be done in the future. There are several alternative treatments to the one described in this study, where conventional antibodies were used. Investigation is required into whether some of the available monoclonal antibodies (Aasted \& Avery 1983, Race et al. 1986, Kierek-Jaszczuk 1986) can prevent pneumonitis in newborn mink kits as well as the conventional antibodies used in this study. If so, hybridoma-antibodies should be used instead of conventional antibodies, as there is always the risk that the conventional antibodies, which are prepared from sera from infected mink, have some residual virus.

Future investigations are also needed to establish whether active immunization (vaccination) with either inactivated ADV or virus protein produced by DNA technology (Mayer et al. 1983) should be used instead of passive antibody treatment. However, in countries where AD eradication programmes take place, it is not advisable to use active immunization, because presence of antibodies is used as an indicator for virus infection. Therefore passive antibody treatment should be used in these countries. In countries with no $\mathrm{AD}$ eradication programmes, active immunization could be performed to prevent pneumonitis in mink kits. Mink farms with high female sterility rates should be kept under observation for development of pneumonitis from the very first moment of birth of mink kits. Furthermore farms such as the one described in this paper, which had ADV-infection at the breeding time, should be kept under observation. It is important for an optimal result of the gammaglobulin treatment that it is given as soon as the first case of pneumonitis is diagnosed. Mink farmers and consultants should be aware of this. 


\section{Acknowledgements}

Mink consultant Hans Henrik Møller is acknowledged for his valuable help with mink death recordings and statistician Jesper Clausen, The Danish Fur Breeders Association, for the statistical treatment of the data. Technical help from Ms. Else Bang Larsen, Ms. Anne Friis Petersen, and Dr. Anders Cohn is greatfully acknowledged. The study was supported by the Danish Veterinary and Agricultural Research Council and the Danish Fur Breeders' Association Research Foundation.

\section{References}

Aasted B: Aleutian disease of mink. Virology and Immunology. Acta path. microbiol. immunol. Scand. Sect. C. 1985, Suppl. 287, Vol. 93.

Aasted B, Alexandersen S, Cohn A, Hansen M: Counter current line absorption immunoelectrophoresis is an alternative diagnostic screening test to counter current immunoelectrophoresis in Aleutian disease (AD) eradication programs. Acta vet. scand. 1986, 27, 410-420.

Aasted B, Avery B, Cohn A: Serological analysis of different mink Aleutian disease virus strains. Arch. Virol. 1984, 80, 11-22.

Alexandersen $S$ : Acute interstitial pneumonia in mink kits: Experimental reproduction of the disease. Vet. Pathol. 1986, 23, 579-588.

Bloom ME, Race RE, Wolfinbarger JB: Characterization of Aleutian disease virus as a parvovirus. J. Virol. 1980, 35, 836-843.

Bøtner AG, Jørgensen PH: An outbreak of excessive neonatal mortality in four Danish mink farms. Acta vet. scand. 1983, 24, 499-511.

Cho HJ, Ingram DG: The antigen and virus of Aleutian disease in mink. J. Imm. Meth. 1974, 4, 217-288.

Jørgensen PH, Bøtner AF: An outbreak of excessive neonatal mortality in four Danish mink farms. Acta vet. scand. 1983, 24, 488-498.

Karstad L, Pridham TJ, Gray DP: Aleutian disease (plasmacytosis) of mink. II. Responses of mink to formalin treated diseased tissue and to subsequent challenge with virulent inoculum. Canad. J. comp. Med. 1963, 27, 124-128.

Kierek-Jaszczuk D, Moennig W, Stolze B, Neth $R$, Tan I, Greiser de Wilke I, Kaaden O-R:
Epitopic mapping of structural and nonstructural Aleutian disease virus proteins. Intervirology 1986, 26, 74-84.

Larsen $S$, Alexandersen $S$, Lund $E$, Have $P$, Hansen $M$ : Acute interstitial pneumonitis caused by Aleutian disease virus in mink kits. Acta path. microbiol. immunol. scand. Sect. A, 1985, 92, 391-393.

Lodmell DL, Portis JL: Immunologic and genetic aspects of Aleutian disease. In: Immunological Defects in Laboratory Animals 2 (eds. Gershwin and Merchant) plenum press, NY \& London 1981, pp 39-75.

Mayer LW, Aasted B, Garon CF, Bloom ME: Molecular cloning of the Aleutian disease virus genome: Expression of Aleutian disease virus antigens by a recombinant plasmid. J. Virol. 1983, 48, 573-579.

Porter DD, Larsen AE, Porter HG: Aleutian disease of mink. Adv. immunol. 1980, 29, 261 -286 .

Porter DD, Larsen AE, Porter HG: The pathogenesis of Aleutian disease of mink. II. Enhancement of tissue lesions following the administration of a killed virus vaccine or passive antibody. J. Immunol. 1972, 109, 1-7. Porter DD, Larsen AE: Aleutian disease of mink. Infectious virus-antibody complexes in the serum. Proc. Soc. exp. Biol. Med. 1967, 126, 680-682.

Race RE, Chesebro B, Bloom ME, Aasted B, Wolfinbarger $J$ : Monoclonal antibodies against Aleutian disease virus distinguish virus strains and differentiate sites of virus replication from sites of viral antigen sequestration. J. Virol. 1986, 57, 285-293.

\section{Sammendrag}

Behandling af nyfodte plasmacytosevirus (ADV) inficerede mink hvalpe med gammaglobulin indeholdende antistoffer mod $A D V$ reducerer mortaliteten af mink hvalpene.

Plasmacytosevirus (Aleutian disease virus (ADV)) kan fremkalde pneumonitis hos nyfødte minkhvalpe (op til 3 uger gamle). I mange tilfælde er denne pneumonitis dødelig, men den kan forebygges ved behandling med antistoffer mod ADV. Nærværende rapport beskriver antistofterapi af 
både eksperimentelt $\mathrm{ADV}$-inficerede minkhvalpe og minkhvalpe fra en farm, hvor en ADV-epidemi udbrød i yngleperioden i foråret 1987. I begge tilfælde havde antistofbehandlingen en gunstig virkning på minkhvalpenes overlevelsesprocent. Der var en overlevelsesprocent på 100 blandt de eksperimentelt inficerede minkhvalpe. Den mest udtalte effekt hos de naturligt inficerede minkhvalpe fandtes hos wildtype hvalpe, hvor dødeligheden var 9,6\% hos hvalpe behandlet med anti- stof mod $16,9 \%$ hos ubehandlede hvalpe $(\mathrm{p}<$ 0.001 ). Det blev generelt fundet, at virkningsgraden af gammaglobulin behandlingen syntes at korrelere med infektionsniveauet af plasmacytosevirus i minkhallerne. Den største virkningsgrad blev fundet i de haller, der havde det højeste ADV infektionspres (standard og wildtype mink), medens der ingen effekt af behandlingen blev fundet for pearl mink, der var i en hal med et lille plasmacytosevirus infektionsniveau.

(Received November 12, 1987; accepted January 13, 1988).

Reprints may be requested from: B. Aasted, Department of Veterinary Virology and Immunology, Royal Veterinary and Agricultural University, Bülowsvej 13, DK-1870 Frederiksberg C, Denmark. 